\title{
INVESTIGATION ON THE AIR-GAS CHARACTERISTICS OF AIR-HYDROGEN MIXER DESIGNED FOR DUAL FUEL - ENGINES
}

\author{
Alaulddin A. Kazum \\ Department of Reconstruction and Projects ${ }^{1}$ \\ alaulddin.abdulqader@uobaghdad.edu.iq \\ Osam H. Attia \\ Department of Reconstruction and Projects ${ }^{1}$ \\ osamhsattai@uobaghdad.edu.iq \\ Ali I. Mosa \\ Department of Mechanical Engineering \\ College of Engineering ${ }^{l}$ \\ ali.i.mosa@uobaghdad.edu.iq \\ Nor Mariah. Adam \\ Department of Science and Technology \\ Universiti Putra Malaysia \\ Bintulu Sarawak Campus \\ Nyabau Road, 97008 Bintulu, Sarawak, Malaysia \\ mariah@upm.edu.my \\ ${ }^{1}$ University of Baghdad \\ Karrada, Al-Jadriya - Baghdad, Iraq
}

\begin{abstract}
High smoke emissions, nitrogen oxide and particulate matter typically produced by diesel engines. Diminishing the exhausted emissions without doing any significant changes in their mechanical configuration is a challenging subject. Thus, adding hydrogen to the traditional fuel would be the best practical choice to ameliorate diesel engines performance and reduce emissions. The air hydrogen mixer is an essential part of converting the diesel engine to work under dual fuel mode (hydrogen-diesel) without any engine modification. In this study, the Air-hydrogen mixer is developed to get a homogenous mixture for hydrogen with air and a stoichiometric air-fuel ratio according to the speed of the engine. The mixer depends on the balance between the force exerted on the head surface of the valve and the opposite forces (the spring and friction forces) and its relation to decrease and increase the fuel inlet. Computational fluid dynamics (CFD) analysis software was utilised to study the hydrogen and airflow behaviour inside the mixer, established by $3.2 \mathrm{~L}$ engine. The Air-hydrogen mixer is examined with different speeds of engine 1000, 2000, 3000 and 4000 RPM. Results showed air-hydrogen mixture was homogenous in the mixer. Furthermore, the stoichiometric air-fuel ratio was achieved according to the speed of the engine, the developed mixer of the AIR-Hydrogen mixing process provides high mixing homogeneity and engines with stoichiometric air-fuel ratios, which subsequently contributes to the high levels of efficiency in engine operation. In summary, the current study intends to reduce the emissions of gases and offer a wide range of new alternative fuels usage. While the performance of the diesel engine with the new air-hydrogen mixer needs to be tested practically.
\end{abstract}

Keywords: AIR hydrogen Mixer, Dual Fuel, hydrogen-diesel, Computational fluid dynamics.

DOI: $10.21303 / 2461-4262.2021 .001722$

\section{Introduction}

Energy is a crucial component of maintaining a modern economy; and it significantly contributes to the growth of the economy. Currently the world is faced with the double crises of environmental degradation and depletion of fossil fuel [1]. Fossil fuel consumption is steadily on the rise, caused by population growth additional to the improvements in the standard of living. Reversibly, burning fossil fuels generates waste materials, mostly emissions to the atmosphere. These waste 
materials are emitted to the atmosphere in the form of dust and combustion fuel gases $\left(\mathrm{HC}, \mathrm{CO}_{2}\right.$, NOx, and $\mathrm{CO}$ ), along with some clinker and ash. The produced waste materials have negative and dangerous effects on both the local and global environment [2,3]. These adverse impacts can be cushioned by using alternative renewable energy produced from natural resources such as biomass, solar heat and light and by using alternative fuels like hydrogen, and NG [4].

Diesel engines are used in various applications as they boast off high thermal efficiency, reliability, high torque, fuel economy, durability, and low emission of carbon dioxide $\left(\mathrm{CO}_{2}\right)$ [5]. However, the main problem areas for engine used diesel fuel is the producing of high emission level of nitrogen oxides (NOx) owing to the elevated localised temperature and also of the particulate matter (PM) emission following its combustion with a heterogeneous mixture of air-fuel ratio [6]. NOx primary dependence on the temperature inside the cylinder is determined by a homogeneity degree in the localised mixture of air-fuel. Despite the fact that there are numerous techniques can be used to decrease the emissions of NOx and PM such as Selective Catalytic Reduction (SCR) and Diesel Particulate Filter (DPF) [7].

As tough devices and catalysts work in retrofitting the vehicles' engines, these techniques work on the basis of using expensive and precious metals. Thus, various compromising techniques have been conducted and recommended in 2014 by J. H. Zhou and his group. These also incorporated the Dual-Fuel-Combustion [8,9]. The effect of nozzle and combustion chamber geometry has been investigated for proper combustion chamber and achieving better thermal efficiency $[8,9]$. Hydrogen $\left(\mathrm{H}_{2}\right)$, which is naturally presented on Earth, has been produced from several resources such as algae, fossil energy, and biomass [10].

Evidently, this promising renewable fuel is an alternative to traditional hydrocarbon fuels (diesel and gasoline). It has several potential usages as it is safe to environmentally friendly and safe to produce. The combustion of $\mathrm{H}_{2}$ does not produce greenhouse gases, deplete of the ozone layer, or pollute the environment by acid rain ingredients [11, 12]. In a compressed ignition engine, adding $\mathrm{H}_{2}$ under the dual-fuel mode has the ability to decrease the emissions of $\mathrm{HC}, \mathrm{CO}$, and PM smoke. In diesel engines, the use of hydrogen under dual-fuel mode where diesel as pilot fuel and hydrogen is a hassle-free way of reducing the heterogeneity degree that results in less emissions of PM and NOx. Dual-fuel engines also enable the development of alternative fuels to attain less pollutant combustion $[6,13]$. One feasible approach in converting diesel engine without modifying too much, to accept hydrogen is to install the Fuel-air mixer before the combustion chamber at the air inlet. The hydrogen fuel and air mixture will enter the combustion chamber in addition to the air intake and is then compressed; meanwhile, the diesel fuel is utilised as a pilot for creating the auto-ignition within the combustion chamber. The conversion of this dual system be able to achieve up to $100 \%$ of diesel or mixture, of $\mathrm{H}_{2}$ and diesel $[14,15]$.

The combustion efficiency, engine performance, the air-fuel ratio and the emission reduction of gases from the engine have a direct proportion to the degree of homogeneous mixing, all of which rely on the mixer design (size and shape) and control mechanism controlling the mixer [16]. Bearing this in mind, the mixer design is crucial; it should be created to meet the air-fuel ratio requirement for multiple loads. The rapid depletion of fossil fuels and increasing concern for the environment and humans forces engine manufacturers and researchers to look for new alternatives. Few researchers tried to design an air-Hydrogen mixer to convert the diesel engine to a dualfuel engine. Therefore, fundamental knowledge on mixing efficiency -air-hydrogen is still scarce. Moreover, most mixers are suitable to work with gasoline engines under bi-engine mode (gasoline or producer gas), whereas only some are suitable to work with diesel engines under the dualfuel mode (diesel-producer gas dual-fuel engine). In addition, according to previous literature, one problem of gaseous mixers is the inability to prepare a homogeneous mixture of air and fuel at a specific air-fuel ratio prior to entering the engine. This issue leads to high brake-specific fuel consumption (BSFC) and high exhaust emissions [17]. The aim of this work is to design a new air- $\mathrm{H}_{2}$ mixer that is suitable for mixing air with $\mathrm{H}_{2}$ to convert the diesel engine to a dual-fuel engine. This new mixer should allow the super homogeneous mixing of gaseous fuel with air according to a range of engine speeds and air-fuel ratio. The mixture homogeneity for hydrogen and air and air-fuel ratio inside new mixer using CFD software was investigated. 


\section{Material and method}

\section{1. Modeling the mechanism of air-hydrogen mixer}

Installing the hydrogen-air mixer aims to help ease the combustion process by introducing a pre-mixed amount of hydrogen-air prior to transferring it to the combustion chamber, and at the same time to adapt the diesel engine to work under dual-fuel mode (hydrogen and diesel or diesel) without more modifications in the engine. This mixer contains different main parts such as the main control body, centred valve, exterior covers, springs, air-inlet, inlet of hydrogen and outlet of the mixture (Fig. 1-3).

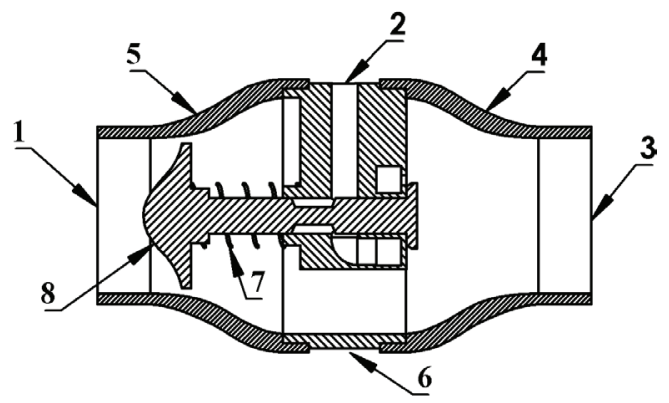

Fig. 1. Air-gas mixer parts: 1 - air inlet; 2 - hydrogen inlet; 3 - mixture outlet; 4, 5 - external cover of mixture; 6 - main controller bod; 7 - spring; 8 - valve
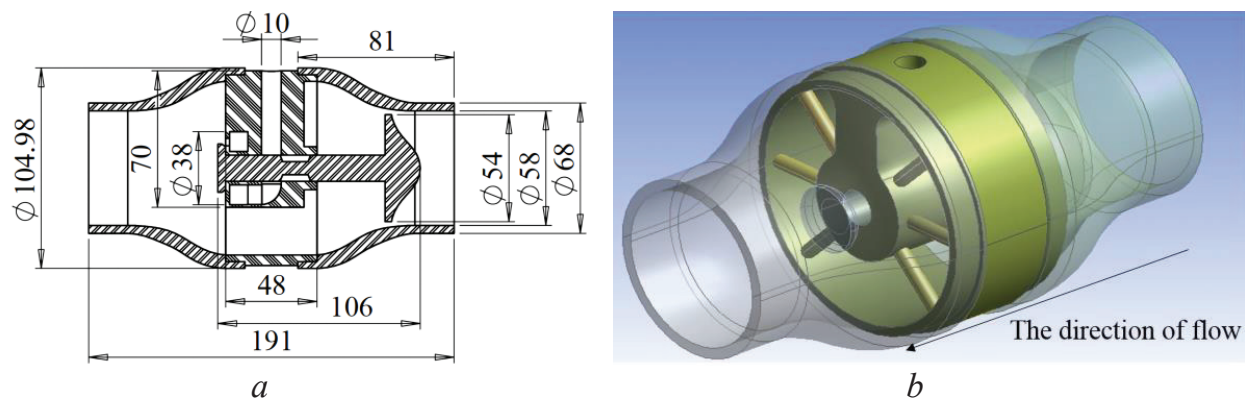

Fig. 2. Dimensions of the air-gas mixer: $a$-schematic view; $b$-isometric view
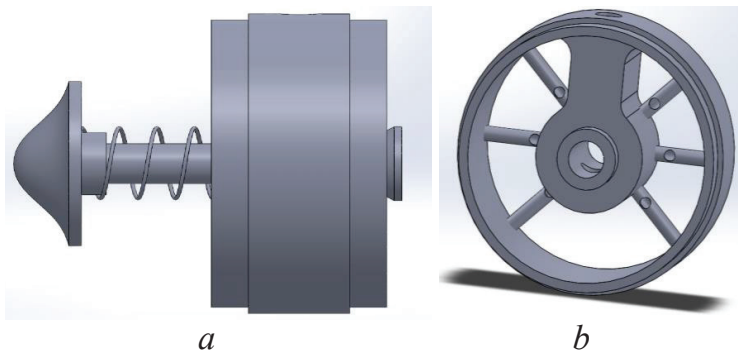

Fig. 3. Mixer main controller body without covers: $a$-isometric view with spring; $b$ - isometric view

The mechanism of the mixer starts at the airflow inside the inlet of air as the sucking procedures that occurred in the engine results in continuous air pressure on the head surface of the valve which is controlled by the speed of the engine). Consequently, the valve will move to the back until achieving the required balance between the air pressure from one side and the spring counter force and the friction force from the other side can be express as the following equation:

$$
F_{\text {axial }}=K X+F_{f},
$$

where $F_{\text {axial }}$ - axial force that will supply on the valve $(\mathrm{N}) ; K$ - stiffness of spring; $X$ - the distance that spring will move by $(\mathrm{mm}) ; F_{f}=$ friction force $(\mathrm{N})$. 
The valve movement controls hydrogen ratio by increasing and decreasing across sectional area of the fuel inlet.

\section{2. Computational fluid dynamics (CFD) method}

One of the approaches utilised to construct and run the experimental simulation virtually is CFD. This approach used commercial software that can save time and cost as it can be run repeatedly without needing to create the model physically. CFD analysis has been successfully implemented for simulation of many engineering problems. In the current study, ANSYS CFD workbench was used for creating a multi-block structural mesh for the problem geometries. In the current study, ANSYS workbench (FLUENT) 16 software package is used for simulation purposes. The associated 3D Navier-Stokes equations flow equation was solved using the finite volume method on the basis of pressure via a fully implicit code. That code is a universal code that has been utilised for modelling many of industrial problems including flow of fluid, transfer of heat (involving radiation), chemical species mixing, turbulence, two-phase flows, moving-rotating bodies multi-step chemistry and several complex physical problems. In this study, the analysis would be achieved for determining the flow field, and the distribution of air/fuel for different geometrical configurations at various rates of air and fuel flow and different engine speeds.

\section{3. Model of Turbulence}

Turbulence can be regarded as flow field fluctuation in time and space that have a critical impact on the characteristics of the flow. Generally, the turbulence takes place when the fluid inertia force is greater than the force due to fluid viscosity. That can be detected by the larger Re. The $k-\varepsilon$ model is the most commonly used model in representing the turbulence in fluid flow analysis works. In this model, $k$ is the variance of fluctuations in velocity and represents the kinetic energy of the turbulence while $\varepsilon$ is the rate dissipation rate velocity fluctuations and the dissipation in turbulence eddy. In order to achieve the objectives of the current work, the Standard model of the $k-\varepsilon /$ high $\mathrm{Re}$ at $300 \mathrm{~K}$ as the isothermal heat transfer temperature.

This model, according to the presented literature, is noticed as the most efficient and consistent model for producing fast and accurate results. The standard function of the wall used in this work is the near wall treatment. This presents more accurate and valid results when Re is high (turbulent flow).

The Solver uses this model will solve the $K$-epsilon equation that consist of two variables $(K-E)$. In addition, the model will solve Navier-Stokes equations, which depend on solving State, momentum conservation, energy conservation, mass conservation, and perfect gas equations as show in the following $[17,18]$.

Mass conservation equation can be express as the follows.

The formula is part of the text, so after a claim must stand semantic mark if the new proposal goes further, then the point, if further clarification is the comma:

$$
\frac{\partial \rho}{\partial t}+\nabla \cdot(\rho \bar{v})=S_{m}
$$

where $\rho$ refers to the fluid density, $v$ refers to the kinematic viscosity and $t$ is the time.

The source $S_{m}$ is defined as the mass that added from the dispersed second phase or any external defined sources to the continuous phase.

Momentum conservation equations can be express as the follows:

$$
\frac{\partial}{\partial t}(\rho \bar{v})+\nabla \cdot(\rho \bar{v} \bar{v})=-\nabla p+\nabla \cdot(\bar{\tau})+\rho \bar{g}+\bar{F}
$$

where $p$ refers to the static pressure, $\bar{\tau}$ refers to the stress tensor, $\rho g$ is the body force due to gravity, and $F$ is external body forces: 


$$
\frac{\partial}{\partial t}(\rho E)+\nabla \cdot(\bar{v}(\rho E+p))=-\nabla \cdot\left(\sum_{j} h_{j} J_{j}\right)+S_{h}
$$

where $E$ - specific energy of fluid, $h$ enthalpy of fluid. Equations of state;

$$
P=P(\rho, T) \text { and } i=i(\rho, T) \text {. }
$$

Equation of perfect gas:

$$
P=\rho R T \text { and } i=C_{v} T \text {, }
$$

where $\rho$ - fluid density, $C_{v}$ - specific heat at constant volume, $P$ - static pressure, $T$ - temperature and $R$ - universal gas constant. The turbulence kinetic energy, $k$;

$$
\frac{\partial}{\partial t}(\rho k)+\frac{\partial}{\partial x_{i}}\left(\rho k u_{i}\right)=\frac{\partial}{\partial x_{i}}\left[\left(\mu+\frac{\mu_{t}}{\sigma_{k}}\right) \frac{\partial k}{\partial x_{i}}\right]+G_{k}-G_{b}-\rho \in-Y_{M}+S_{k} .
$$

The equation for $\varepsilon$ without compressibility is given by:

$$
\frac{\partial}{\partial t}(\rho \in)+\frac{\partial}{\partial x_{i}}\left(\rho \in u_{i}\right)=\frac{\partial}{\partial x_{i}}\left[\left(\mu+\frac{\mu_{t}}{\sigma_{\epsilon}}\right) \frac{\partial \in}{\partial x_{i}}\right]+C_{1 \in} \frac{\epsilon}{k}\left(G_{k}+G_{3 \in} G_{b}\right)-C_{2 \in} \rho \frac{\epsilon^{2}}{K}+S_{\epsilon},
$$

where $G_{k}$ represents the generation of turbulence kinetic energy due to the mean velocity gradients, $\mathrm{Gb}$ is the generation of turbulence kinetic energy due to buoyancy, YM represents the contribution of the actuating dilatation incompressible turbulence to the overall dissipation rate, $C_{1 \in}, C_{2 \in}, \sigma_{k}, \sigma_{\epsilon}$ and $C_{3 \in}$ are constants, $\mu$ is molecular viscosity, $\mu$ is turbulent viscosity.

\section{4. Mixing process without reaction}

This requires solving the other equations for mixture fractions or species mass fraction. Within this simulation, hydrogen and air are assumed to have no reaction with one another [19, 20].

\section{4. 1. Air-fuel ratio}

This ratio was one of the critical factors for mixer designing. The minimum amount of air required for completing combustion of fuel called the stoichiometric air-fuel ratio.

In present work, substitution ratios of hydrogen fuel by energy by diesel energy in dual-fuel engine is $50 \%$, the hydrogen percentage value (hydrogen $\%$ ) can be calculated according on the following equation:

$$
\text { hydrogen } \%=\frac{\dot{m}_{h} \times L H V_{h}}{\dot{m}_{D} \times L H V_{h}+\dot{m}_{h} \times L H V_{h}},
$$

where $\dot{m}_{D}$ and $\dot{m}_{h}$ are the mass flow rate of diesel and hydrogen fuels in $\mathrm{kg} / \mathrm{h}$, respectively. $L H V_{h}$ and $L H V_{D}$ represent the lower heating value $(L H V)$ of diesel and the hydrogen fuels in $\mathrm{MJ} / \mathrm{kg}$, respectively. Therefore, the Air-hydrogen ratio inside the mixer is 74.76 .

\section{4. 2. Boundary condition}

There are three boundary conditions considered. The air inlet boundary, the hydrogen inlet boundary and the outlet boundary [19].

- the condition of the air inlet: at the air inlet, the velocity is defined as a constant inside the mixer. The mass fraction value is (1) and (0) for the air and the hydrogen, respectively;

- the hydrogen inlet boundary: at this inlet, fixed static pressure boundary conditions are applied for different engine speeds. The value of the mass fraction for the air is (0) and for the hydrogen is (1); 
- the outlet boundary: at this boundary, pressure is considered to be fixed as this condition provides the continuity in the pressure system by keeping the inlet and outlet pressures balanced. Inflow is can be maintained even in cases where the pressure of the outlet boundary is fixed.

\section{4. 3. Meshing}

The major and vital component of CFD is meshing. After meshing is selected, the fluid flow equations can be resolved in grid cells or grid elements, which the mesh has created. In this work, Grid independent test (GIT) for the mesh was tested on at engine speed (4000 rpm) to choose the suitable elements and nodes numbers, that gives accurate results and saves the time of the simulation and then it will be applied with four cases of engine speed (1000-4000 rpm). Four independent cases of meshing were chosen to conduct the grid-independent test (Table 1). The four meshing cases were achieved utilising tetrahedrons method, patch independent, and the curvature as presented in Fig. 4. Tetrahedral shapes are used for dividing the mixer. Table 2 presents the boundary condition used for checking the GIT in the four cases of meshing.

For all cases above, the grid-independent test was accomplished through contrasting the uniformity index findings at the mixer outlet as shown in Fig. 5.

Table 1

Nodes and elements number for grid dependence test for simulation at $4000 \mathrm{rpm}$ engine speed

\begin{tabular}{lcc}
\hline Cases & Elements & Nodes \\
\hline Case 1 & 272796 & 57542 \\
Case 2 & 369963 & 77395 \\
Case3 & 466786 & 90523 \\
Case 4 & 585603 & 128231
\end{tabular}

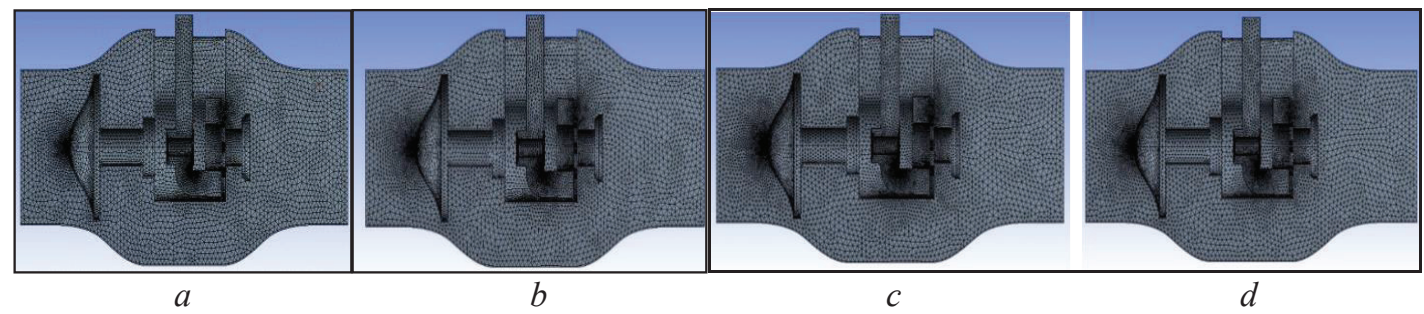

Fig. 4. Meshing cases used in grid dependency test: $a$-case 1, $b$ - case 2, $c$ - case 3, $d$ - case 4

Table 2

Boundary condition for grid dependence test for the simulation on at $4000 \mathrm{rpm}$ engine speed

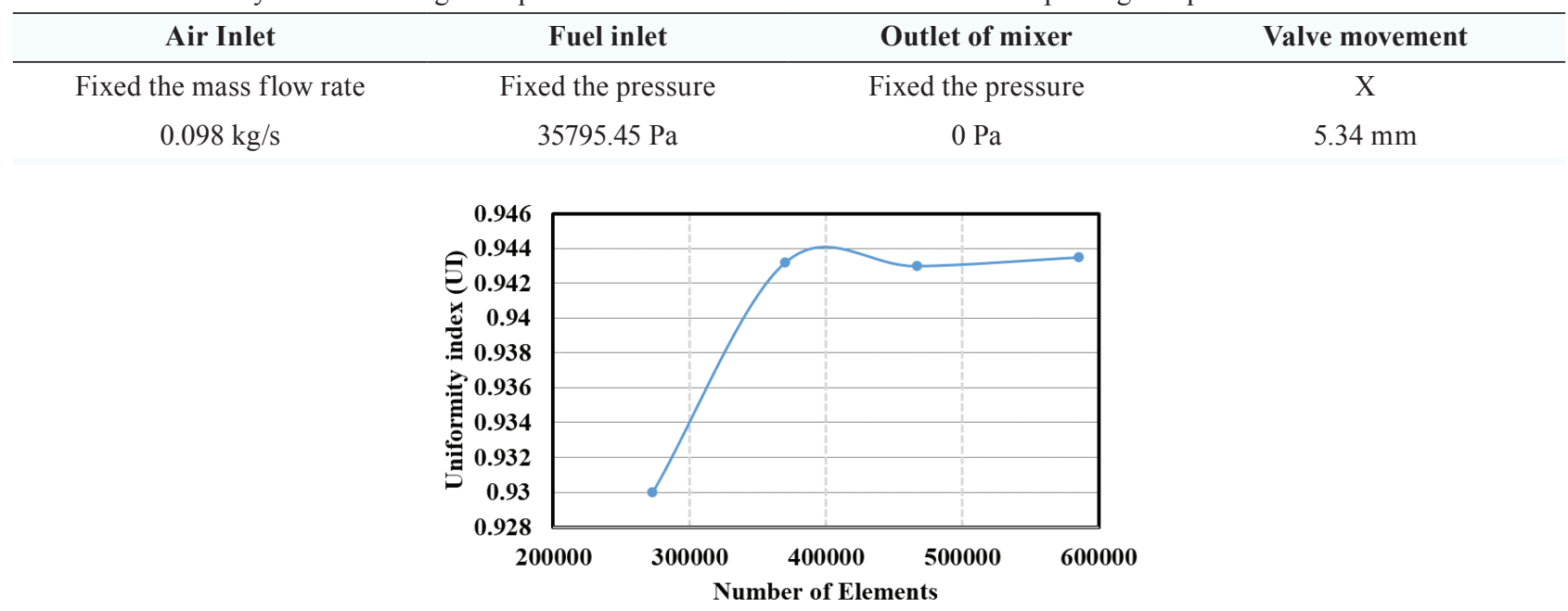

Fig. 5. Grid dependence test results 
According to GIT, Case 3 was chosen to apply on all engine speeds (1000 rpm-4000 rpm) depending on GIT.

\section{Results and discussion}

\section{1. Simulation results}

The air-fuel mixer was considered for different values of engine speeds from $1000 \mathrm{rpm}$ to $4000 \mathrm{rpm}$ that was achieved after the process of boundary condition stabilising at the inlets and outlet of the mixer based on its consistent engine speed. The valve movement inside the air-fuel mixer was studied by changing its position until obtaining the suitable stoichiometry air-fuel ratio 74.71.

Pressure, mass flow rate, mass fraction, uniformity index and some other characteristics of mixture were studied inside the mixer. In addition, the directed force on the valve head and its relation to valve displacement was also studied.

Fig. 6-8 show the variation of mass flow rate for hydrogen, diesel, air under different engine speed. As exhibited in Fig. 6-8, It was found that the air flow rate and fuel consumption are directly proportional to the engine speed. That means, when the engine speed increases, the airflow rate will increase inside the engine consequent high fuel consumption. Furthermore, stoichiometric ratio of air-fuel (74.76) was achieved based on the engine speed.

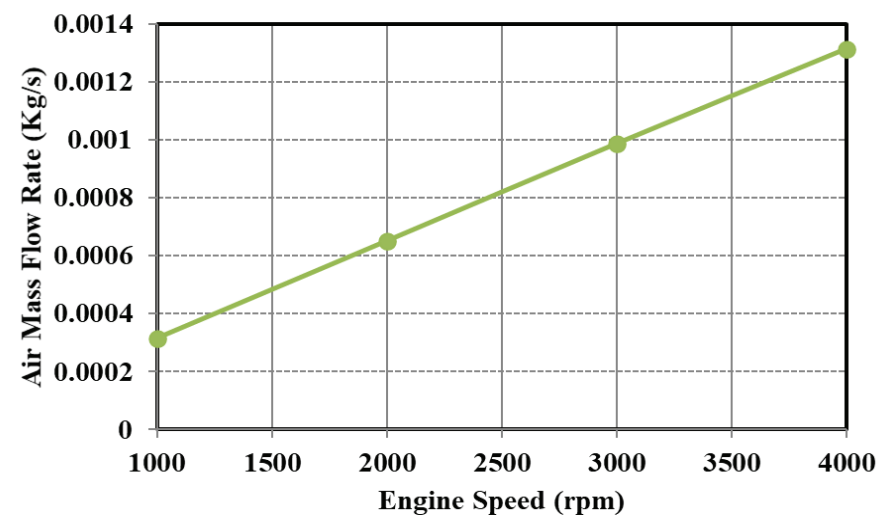

Fig. 6. Variation of air mass flow rate with engine speed

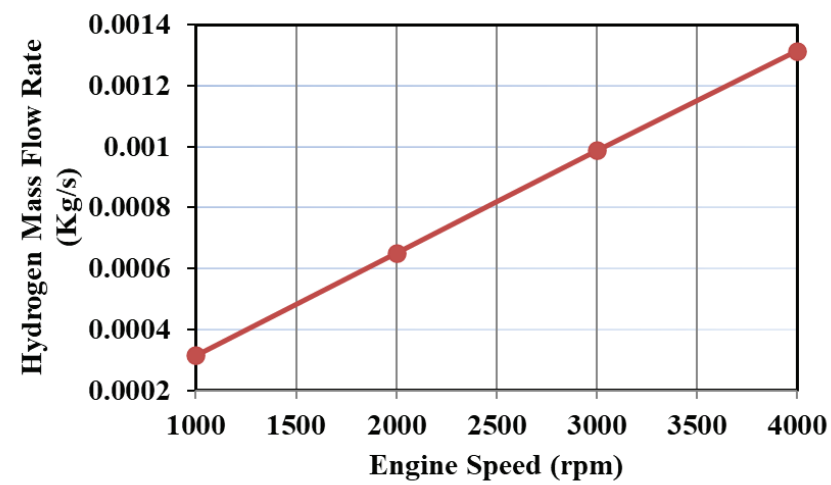

Fig. 7. Flow rate variation of hydrogen mass concerning the engine speed

Fig. 9 shows the relationship between force and the displacement on the head of the valve. As exhibited in Fig. 9, it was noted that the air flow inside the mixer will increase with increasing the speed of the engine, which consequent increase the directed force on the valve head which in turn increase valve displacement, and vice versa. While Fig. 10 presents the relationship between valve displacement and the engine speed under air- $\mathrm{H}$ ratio 74.71, at constant pressure at the $\mathrm{H}_{2}$ inlet of the new mixer (35795.45 Pa). Fig. 11 shows that the air amount increases as engine speed increase, thereby increasing the forward displacement of the valve to allow increased flow of the fuel to the mixer and achieve the required ratios of mixing. 


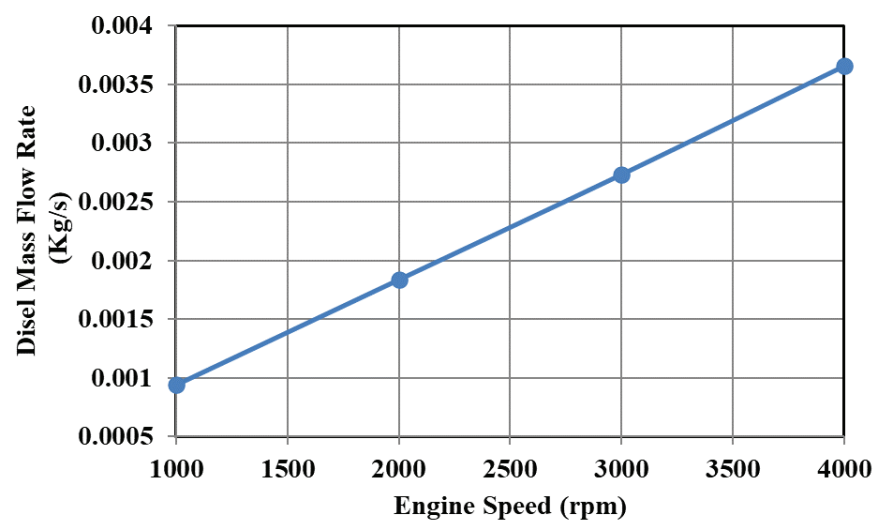

Fig. 8. Flow rate variation of diesel concerning engine speed

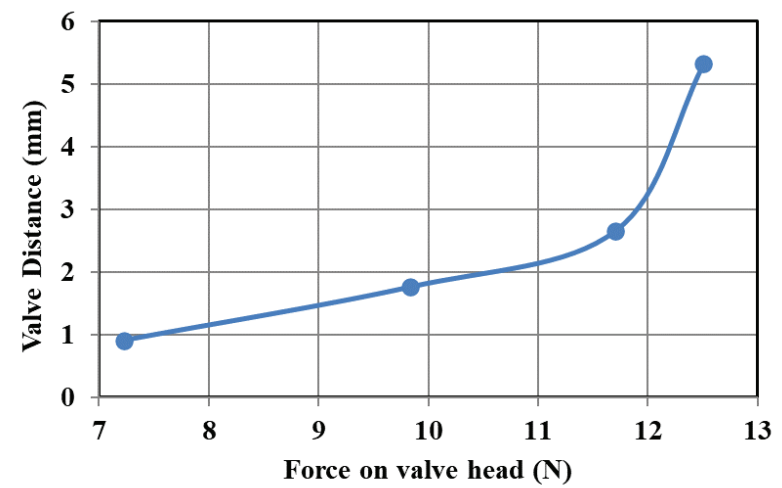

Fig. 9. Relation between displacement and force on valve head

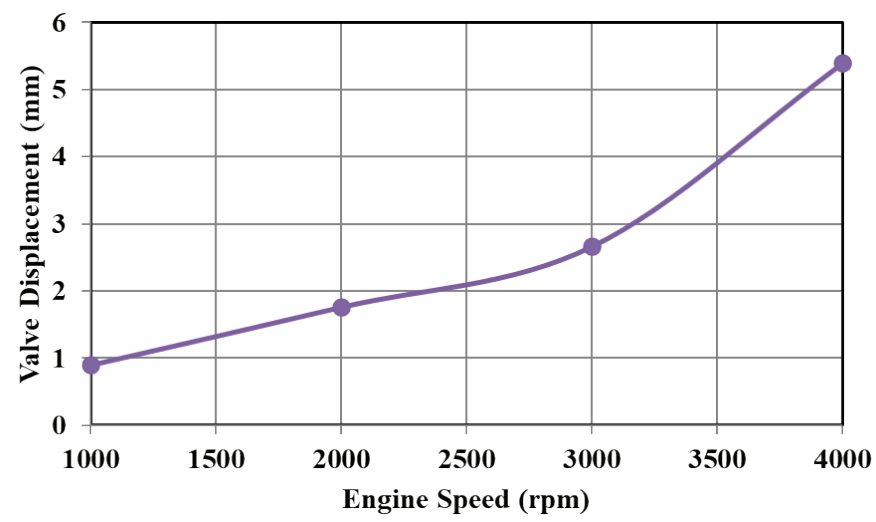

Fig. 10. Relationship between valve displacement and engine speed

Four cases were used in this study to explain the distribution of pressure, velocity, uniformity index and methane mass fraction; each case represent one specific speed of the engine (1000 to 4000) as below:

\section{2. Pressure}

Fig. 11 illustrates the static pressure distribution of (color contours) on the YZ plane inside model of the mixer.

As exhibited in Fig. 11 the highest value of the static pressure appears at the gas inlet, when the engine speed is constant. Furthermore, the applied pressure to the head of the valve is higher than the pressure behind the valve head. In addition, it observed a variable pressure distribution inside the mixer. Moreover, the speed of the engine and displacement of the valve meaningfully affect the distribution of the pressure inside the mixer. 


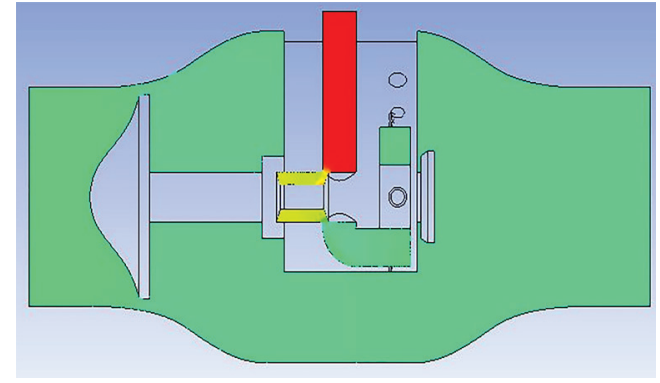

$a$

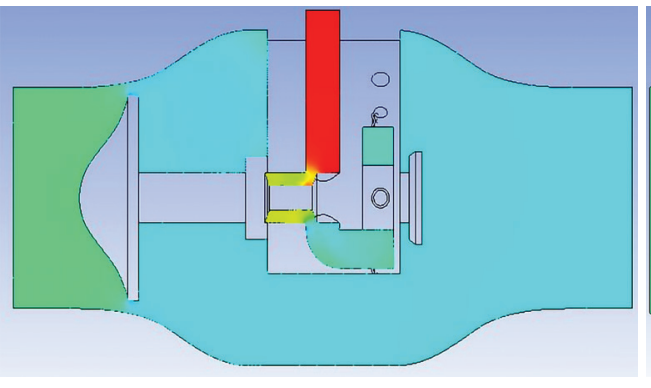

$c$

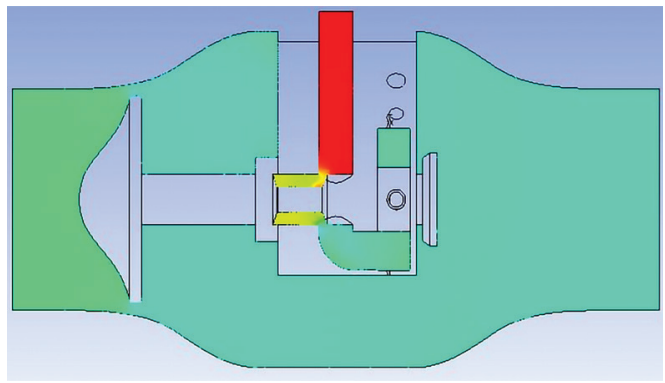

$b$

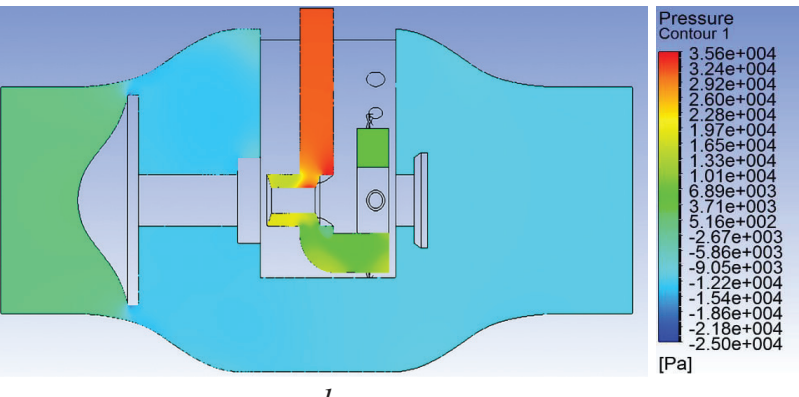

$d$

Fig. 11. Pressure distribution of on YZ plane inside the mixer: $a-1000 \mathrm{rpm} ; b-2000 \mathrm{rpm}$; $c-3000 \mathrm{rpm} ; d-4000 \mathrm{rpm} ; e$ - pressure contour legend

\subsection{Velocity}

Fig. 12 illustrates the velocity distribution of (colour contours) in the YZ plane inside the model of mixer. The Fig. 12 shows that a variable velocity distribution happens inside the mixer for different values of the speeds and displacement of the valve. In furthermore, when the engine speed maintained constant, the velocity before the head of the valve is smaller than that corresponding on the valve head sides. Moreover, the speed of the engine meaningfully affects the distribution of velocity inside the mixer. Specifically, air velocity increases with the speed increasing of the engine.

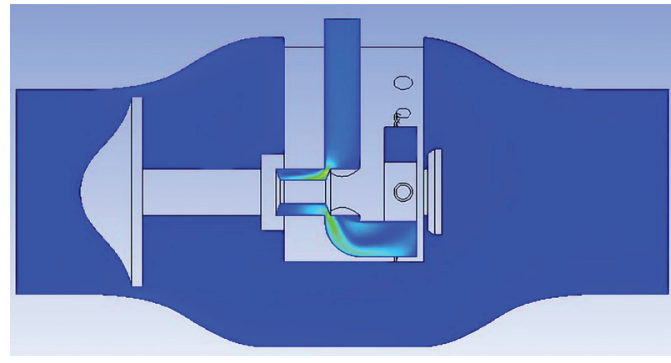

$a$

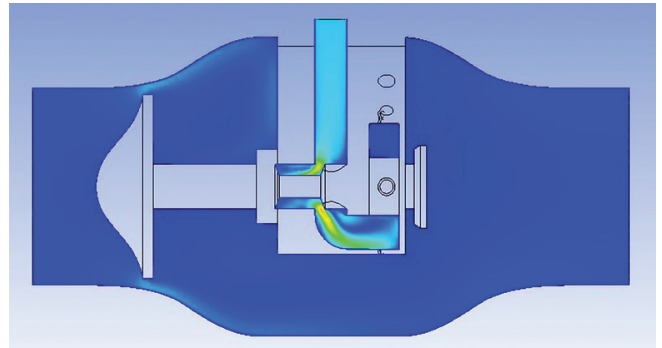

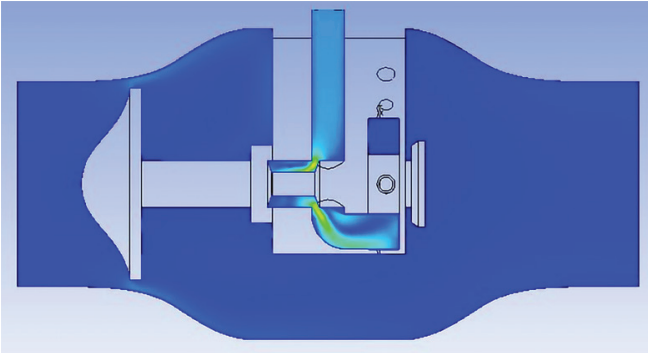

$b$

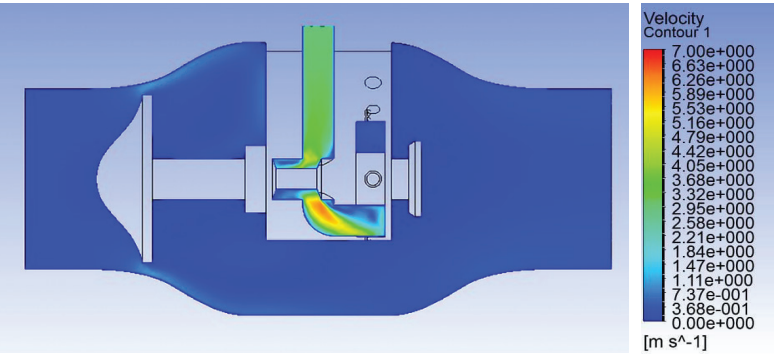

d

Fig. 12. Velocity distribution of $Y Z$ plane inside the mixer: $a-1000 \mathrm{rpm} ; b-2000 \mathrm{rpm}$; $c-3000 \mathrm{rpm} ; d-4000 \mathrm{rpm} ; e-$ velocity contour legend 
Furthermore, the inlet area of the fuel that is connected directly to the valve increases with forwarding valve movement, consequently increasing the hydrogen velocity at the manifold of the gas inside the mixer.

\section{4. Distribution of the hydrogen mass fraction}

Fig. 13 explained the distribution of the mass fraction of hydrogen at the outlet of the mixer. According to the Fig. 13, it was found that the air-hydrogen mixer shows the best homogeneity and the highest propagation rate at the mixer outlet are obtained. Fig. 14 relationship between the UI and engine speeds under air-H ratio 74.71 .

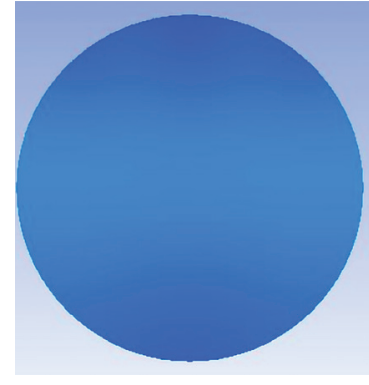

$a$

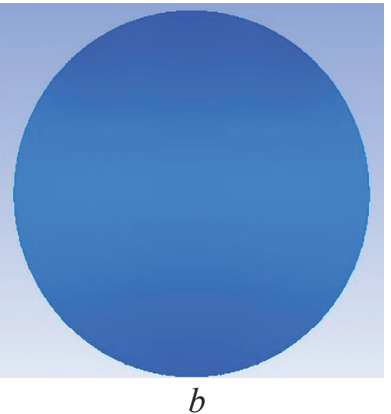

$b$

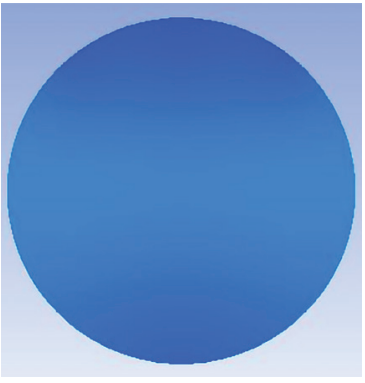

C

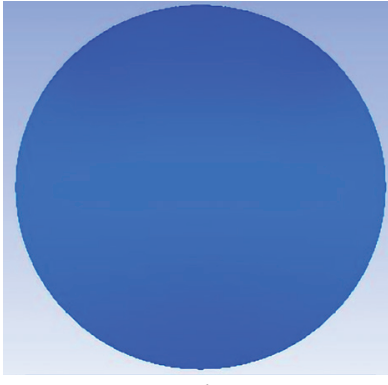

$d$

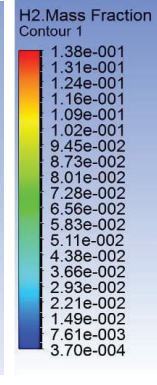

$e$

Fig. 13. Hydrogen mass fraction contour at mixer outlet: $a-1000 \mathrm{rpm} ; b-2000 \mathrm{rpm}$; $c-3000 \mathrm{rpm} ; d-4000 \mathrm{rpm} ; e-\mathrm{H}_{2}$ mass fraction contour legend

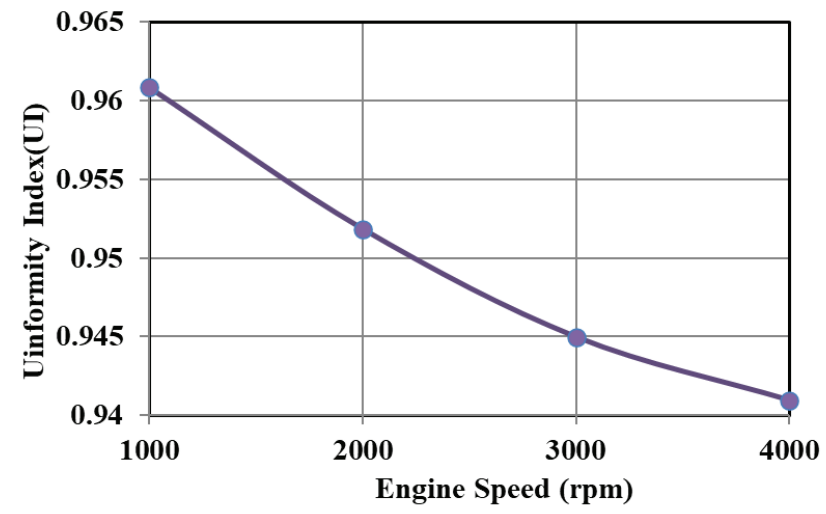

Fig. 14. The relationship between the engine speed uniformity index

From the Fig. 14 it is shown that the UI reduces with increasing engine speed. This result was due to insufficient time to mix gaseous fuel with air when the engine speed increased.

\section{5. Discussion of simulation results}

This study contributes to enhance the fuel economy, enhancing engine performance and reducing emissions by designing the new air-fuel mixer. Moreover, this study contributes to improve the homogeneity $(\mathrm{UI}>0.9$ ) of mixture between air and hydrogen fuel inside the new mixer according to various engine speeds and control on the air and fuel ratio inside the mixer accurately at different engine speeds. the air-H new mixer is suitable for working with dual-fuel engines (diesel-H) and bi-fuel engines (gasoline or alternative fuels). Furthermore, this study has achieved the follows:

1. The new air-H mixer is designed for 4 cylinders, 4 strokes, and 3.168-liter capacity and it is suitable to work with different engine speeds (1000, 2000, 3000, and $4000 \mathrm{rpm}$ ).

2. ANSYS WORKBENCH software (fluent software) was used as tools to create a new mixer model and also to investigate the mixing characteristics, flow, pressure, and velocity for air and hydrogen fuel under 74.71 air-fuel ratio and different engine speeds (1000, 2000, 3000, and $4000 \mathrm{rpm})$. 
While the limitation of this study can be summarized as follows:

1. This study did not deal with the materials of the mixer; hence, this could be a topic for future work.

2. The performance of the diesel engine with the new air-hydrogen mixer needs to be tested practically.

Thus, the developed mixer of the AIR-Hydrogen mixing process provides high mixing homogeneity and engines with stoichiometric air-fuel which subsequently contributes to the high levels of efficiency in engine operation.

\section{Conclusion}

A hydrogen-air mixer for dual fuel engine was created and analysed through the employment of ANSYS/FLUENT/CFD software. The hydrogen-air mixer has been developed to give suitable stoichiometry air-fuel ratio, which corresponds to a particular engine speed. In addition, it will create a homogenous and regular mixture. Accordingly, combustion efficiency has a direct relationship with the mixture's homogeneity level which agree with [17] conclusion. In this condition, the mixture will be entirely burned in the chamber of combustion, causing little emissions as observed from [20]. Stoichiometry air-fuel ratio is one significant factor that has to be considered seriously in the mixer-designing phase. A high-quality mixer must be used to provide optimum condition and environment for the operation of the engine. The results of the presented study illustrated that there is a noticeable homogeneity in the mixture of the air-hydrogen inside the mixer which is identical with [20] outcomes. Thus, the developed mixer of the AIR-Hydrogen mixing process provides high mixing homogeneity and engines with stoichiometric air-fuel ratios as recommended clarifications, which subsequently contributes to the high levels of efficiency in engine operation. Furthermore, stoichiometric ratio of the air-fuel was achieved according to the engine speed. The study anticipates decreasing emissions of the gases. Moreover, it targets to provide a wider range of new substitute fuels usage.

\section{Acknowledgments}

We would like to express our thanks to our colleagues from [faculty of engineering/University Putra Malaysia] and [faculty of engineering/University of Baghdad] who provided insight and expertise that greatly assisted the research.

\section{References}

[1] Darade, P., Dalu, R. (2013). Investigation of Performance and Emissions of CNG Fuelled VCR Engine. International Journal of Emerging Technology and Advanced Engineering (IJETAE), 3 (1), 77-81.

[2] Akansu, S. O., Dulger, Z., Kahraman, N., Veziroğlu, T. N. (2004). Internal combustion engines fueled by natural gas - hydrogen mixtures. International Journal of Hydrogen Energy, 29 (14), 1527-1539. doi: https://doi.org/10.1016/j.ijhydene.2004.01.018

[3] Bora, B. J., Saha, U. K., Chatterjee, S., Veer, V. (2014). Effect of compression ratio on performance, combustion and emission characteristics of a dual fuel diesel engine run on raw biogas. Energy Conversion and Management, 87, 1000-1009. doi: https:// doi.org/10.1016/j.enconman.2014.07.080

[4] Bora, B. J., Debnath, B. K., Gupta, N., Saha, U., Sahoo, N. (2013). Investigation on the flow behaviour of a venturi type gas mixer designed for dual fuel diesel engines. International Journal of Emerging Technology and Advanced Engineering, 3 (3), 202-209.

[5] Alrazen, H. A., Abu Talib, A. R., Adnan, R., Ahmad, K. A. (2016). A review of the effect of hydrogen addition on the performance and emissions of the compression - Ignition engine. Renewable and Sustainable Energy Reviews, 54, 785-796. doi: https://doi.org/10.1016/j.rser.2015.10.088

[6] Yang, Z., Chu, C., Wang, L., Huang, Y. (2015). Effects of H2 addition on combustion and exhaust emissions in a diesel engine. Fuel, 139, 190-197. doi: https://doi.org/10.1016/j.fuel.2014.08.057

[7] Chintala, V., Subramanian, K. A. (2013). A CFD (computational fluid dynamics) study for optimization of gas injector orientation for performance improvement of a dual-fuel diesel engine. Energy, 57, 709-721. doi: https://doi.org/10.1016/ j.energy.2013.06.009

[8] Zhou, J. H., Cheung, C. S., Leung, C. W. (2014). Combustion, performance and emissions of a diesel engine with $\mathrm{H}_{2}, \mathrm{CH}_{4}$ and $\mathrm{H}_{2}-\mathrm{CH}_{4}$ addition. International Journal of Hydrogen Energy, 39 (9), 4611-4621. doi: https://doi.org/10.1016/j.ijhydene.2013.12.194 
[9] Sahoo, B. B., Sahoo, N., Saha, U. K. (2009). Effect of engine parameters and type of gaseous fuel on the performance of dual-fuel gas diesel engines - A critical review. Renewable and Sustainable Energy Reviews, 13 (6-7), 1151-1184. doi: https:// doi.org/10.1016/j.rser.2008.08.003

[10] Yaliwal, V. S., Banapurmath, N. R., Gireesh, N. M., Hosmath, R. S., Donateo, T., Tewari, P. G. (2016). Effect of nozzle and combustion chamber geometry on the performance of a diesel engine operated on dual fuel mode using renewable fuels. Renewable Energy, 93, 483-501. doi: https://doi.org/10.1016/j.renene.2016.03.020

[11] Paul, A., Panua, R. S., Debroy, D., Bose, P. K. (2015). An experimental study of the performance, combustion and emission characteristics of a CI engine under dual fuel mode using CNG and oxygenated pilot fuel blends. Energy, 86, 560-573. doi: https://doi.org/10.1016/j.energy.2015.04.050

[12] Liu, J., Zhang, X., Wang, T., Zhang, J., Wang, H. (2015). Experimental and numerical study of the pollution formation in a diesel/CNG dual fuel engine. Fuel, 159, 418-429. doi: https://doi.org/10.1016/j.fuel.2015.07.003

[13] Alrazen, H. A., Abu Talib, A. R., Ahmad, K. A. (2016). A two-component CFD studies of the effects of H2, CNG, and diesel blend on combustion characteristics and emissions of a diesel engine. International Journal of Hydrogen Energy, 41 (24), 10483-10495. doi: https://doi.org/10.1016/j.ijhydene.2015.07.097

[14] Szwaja, S., Grab-Rogalinski, K. (2009). Hydrogen combustion in a compression ignition diesel engine. International Journal of Hydrogen Energy, 34 (10), 4413-4421. doi: https://doi.org/10.1016/j.ijhydene.2009.03.020

[15] Zhou, J., Cheung, C., Leung, C. (2013). Combustion and emission of a compression ignition engine fueled with diesel and hydrogen-methane mixture. World Academy of Science, Engineering and Technology International Journal of Mechanical and Mechatronics Engineering, 7 (8), 1653-1658.

[16] Hairuddin, A. A., Yusaf, T., Wandel, A. P. (2014). A review of hydrogen and natural gas addition in diesel HCCI engines. Renewable and Sustainable Energy Reviews, 32, 739-761. doi: https://oi.org/10.1016/j.rser.2014.01.018

[17] Mahmood, H. A., Mariah Adam, N., Sahari, B. B., Masuri, S. U., Ahmed, H. E. (2019). An Investigation of Air-Gas Mixer Types Designed for Dual Fuel Engines: Review. Journal of Engineering and Applied Sciences, 14 (4), 1014-1033. doi: https:// doi.org/10.36478/jeasci.2019.1014.1033

[18] Mahmood, H. A., Adam, N. M., Sahari, B., Masuri, S. (2016). Investigation On The Air-Gas Characteristics Of Air-Gas Mixer Designed For Dual Fuel-Engines. International Journal of Control Theory and Applications, 9 (30), 195-216.

[19] Mahmood, H. A., Adam, N. M., Sahari, B. B., Masuri, S. U. (2017). New Design of a CNG-H2-AIR Mixer for Internal Combustion Engines: An Experimental and Numerical Study. Energies, 10 (9), 1373. doi: https://doi.org/10.3390/en10091373

[20] Mahmood, H. A., Adam, N. M., Sahari, B. B., Masuri, S. U. (2017). Design of Compressed Natural Gas-Air Mixer for Dual Fuel Engine Using Three-Dimensional Computational Fluid Dynamics Modeling. Journal of Computational and Theoretical Nanoscience, 14 (7), 3125-3142. doi: https://doi.org/10.1166/jctn.2017.6605

How to cite: Kazum, A. A., Attia, O. H., Mosa, A. I., Adam, N. M. (2021). Investigation on the air-gas characteristics of airhydrogen mixer designed for dual fuel - engines. EUREKA: Physics and Engineering, 2, 66-77. doi: http://doi.org/10.21303/ 2461-4262.2021.001722 